\title{
Authentication of pomegranate juice concentrate using FTIR spectroscopy and chemometrics
}

\author{
Hasan Vardin ${ }^{\mathrm{a}}$, Abdullatif Tay ${ }^{\mathrm{b}}$, Banu Ozen ${ }^{\mathrm{c}, *}$, Lisa Mauer ${ }^{\mathrm{d}}$ \\ ${ }^{a}$ Harran University, Department of Food Engineering, Sanliurfa, Turkey \\ ${ }^{\mathrm{b}}$ Global Technology and Quality, Kraft Foods Global Inc., Glenview, IL, United States \\ ${ }^{\mathrm{c}}$ Izmir Institute of Technology, Department of Food Engineering, Urla-Izmir, Turkey \\ ${ }^{\mathrm{d}}$ Purdue University, Food Science Department, West Lafayette, IN, United States
}

Received 12 June 2007; received in revised form 17 August 2007; accepted 8 November 2007

\begin{abstract}
Fourier transform infrared (FTIR) spectroscopy and chemometric techniques were used to detect the adulteration of pomegranate juice concentrate (PJC) with grape juice concentrate (GJC). The main differences between PJC and GJC infrared spectra occurred in the $1780-1685 \mathrm{~cm}^{-1}$ region, which corresponds to $\mathrm{C}=\mathrm{O}$ stretching. Principal component analysis of the spectra was used to: (1) differentiate pure PJC and GJC samples and (2) classify adulterated (containing 2-14\% vol/vol GJC) and pure PJC samples. Two principal components explained $99 \%$ of the variability in each of these applications. Partial least square analysis of the spectra resulted in prediction of the GJC adulterant concentration in PJC with a correlation coefficient, $R^{2}$, of 0.9751 . Partial least square analysis of spectra could also predict \% titratable acidity and total solids in PJC with correlation coefficients of 0.9114 and 0.9916 , respectively. Therefore, FTIR and chemometrics provide a useful approach for authenticating pomegranate juice concentrate.
\end{abstract}

(C) 2007 Elsevier Ltd. All rights reserved.

Keywords: Pomegranate; Adulteration; Infrared spectroscopy

\section{Introduction}

The pomegranate (Punica granatum) is a good source of anthocyanins (delphinidin, cyanidin, and pelargonidin) and other phenolic compounds (including hydrolyzable tannins such as punicalin, pedunculagin, punicalagin, gallagic, and ellagic acid), organic acids, and antioxidant activity (Gil, Tomas-Barberan, Hess-Pierce, Holcroft, \& Kader, 2000; Noda, Kaneyuki, Mori, \& Packer, 2002; Poyrazoglu, Gokmen, \& Artik, 2002). Pomegranates have been found to be effective in reducing several heart risk factors, including low density lipoprotein oxidation, macrophage oxidative status, and foam cell formation, all of which are steps in atherosclerosis and heart disease (Aviram et al., 2002, 2000). Consuming pomegranate juice may also have cancer-che-

\footnotetext{
* Corresponding author. Tel.: +90 232750 6319; fax: +90 2327506196.

E-mail address: banuozen@iyte.edu.tr (B. Ozen).
}

mopreventive and chemotherapeutic effects against prostate cancer in humans (Malik et al., 2005). Increasing interest in consumption of pomegranates both in fresh and processed form could be attributed to these beneficial health effects, as a result, many food products containing pomegranates and pomegranate juice are entering the market.

Pomegranates have been classified into three varietal groups (sweet, sour-sweet, and sour) based on sensory characteristics and sugar and acid compositions (Cemeroglu, Artik, \& Erbas, 1992; Melgarejo, Salazar, \& Artes, 2000). In the Southeast region of Turkey, the sour and sour-sweet varieties are mainly utilized in concentrated form. The chemical composition of pomegranates has shown significant variation based on cultivar, growing region, maturity, environmental conditions, and storage and handling practices (Cemeroglu et al., 1992; Cemeroglu, Artik, \& Yunculer, 1988; Melgarejo et al., 2000; Mirdehghan \& Rahemi, 2007; Unal, Velioglu, \& Cemeroglu, 1995). Unfortunately, 
the adulteration of pomegranate juice and pomegranate juice concentrate (PJC) with the less expensive grape juice concentrate (GJC) has become a concern. Therefore, analytical techniques are needed that are able to detect this type of adulteration, even in the presence of chemical composition variations.

Attenuated total reflection (ATR)-Fourier transform infrared (FTIR) spectroscopy techniques have potential quantitative quality control applications for food analyses. FTIR-ATR provides a simple and reproducible means of handling products in the form of liquids and pastes, the analyses are nondestructive, and the sampling takes less than $5 \mathrm{~min}$. In combination with chemometric techniques, FTIR-ATR methods have been successfully used for the detection of adulteration of fruit purees, honey, and oils (Irudayaraj, Xu, \& Tewari, 2003; Ozen, Weiss, \& Mauer, 2003; Tay, Singh, Khrisnan, \& Gore, 2002).

The objective of this study was to evaluate the ability of FTIR-ATR methods and chemometric analyses to detect adulteration of pomegranate juice concentrate with grape juice concentrate.

\section{Materials and methods}

\subsection{Preparation of juice concentrates}

Seventeen commercial pomegranate juice concentrate (PJC) samples were collected from four different regions of Southeast Turkey (Sanliurfa, Gaziantep, Hatay and Adana). PJC samples were also prepared in the laboratory from fruits of various sour and sour-sweet pomegranate cultivars obtained from the Harran plain of Turkey. For each sample, $10 \mathrm{~kg}$ of pomegranate was washed and pressed in a manually operated packaged press. Clarification of the extracted juice was carried out according to Vardin and Fenercioglu (2003). The juice was concentrated to the final total soluble solids concentration shown in Table 1 in a rising film evaporator (Armfield Ltd., Ringwood, UK) at $70^{\circ} \mathrm{C}$ under vacuum. For the preparation of GJC, grapes (Siverek type) were also pressed and the juice was concentrated under the same conditions. All juice concentrates were stored at room temperature. Intentionally adulterated samples were prepared by adding GJC into $\mathrm{PJC}$ at $2-14 \%$ ( $\mathrm{vol} / \mathrm{vol})$.

\subsection{Titratable acidity, $p H$, and total soluble solids measurements}

Titratable acidity was determined according to the AOAC method 22.060 (AOAC, 1980). A $2 \mathrm{ml}$ aliquot of PJC or GJC was diluted with $20 \mathrm{ml}$ distilled water, and then total titratable acidity was determined potentiometrically by titrating the sample with $0.1 \mathrm{NaOH}$ until the $\mathrm{pH}$ reached 8.1. Results are expressed in terms of $\%$ citric acid. The $\mathrm{pH}$ of juice samples was measured with a $\mathrm{pH}$ meter (Fisher Sci., Denver). Total soluble solids (\%) were measured by using a refractometer (Atago, Tokyo) at $24^{\circ} \mathrm{C}$.
Table 1

$\mathrm{pH}, \%$ total titratable acidity, and total soluble solids results for pomegranate juice concentrate (PJC) and grape juice concentrate (GJC) samples

\begin{tabular}{|c|c|c|c|}
\hline Sample & $\mathrm{pH}$ & TTA ( $\%$ citric acid) & TSS \\
\hline \multicolumn{4}{|c|}{ PJC samples } \\
\hline$N 3^{\mathrm{a}}$ & 2.6 & 9.5 & 66.5 \\
\hline $\mathrm{N} 4^{\mathrm{a}}$ & 2.62 & 8.7 & 68.4 \\
\hline $\mathrm{N} 6^{\mathrm{a}}$ & 2.9 & 6.7 & 68 \\
\hline $\mathrm{N} 7^{\mathrm{a}}$ & 2.23 & 11.2 & 60.6 \\
\hline $\mathrm{N} 8^{\mathrm{a}}$ & 2.29 & 12.53 & 67.8 \\
\hline$N 9^{\mathrm{a}}$ & 2.1 & 13.3 & 66.4 \\
\hline $\mathrm{N} 10^{\mathrm{a}}$ & 2.9 & 5.8 & 70.2 \\
\hline $\mathrm{N} 15^{\mathrm{a}}$ & 2.7 & 9.1 & 69.5 \\
\hline $\mathrm{A} 22^{\mathrm{b}}$ & 2.32 & 14.27 & 65.8 \\
\hline $\mathrm{A} 23^{\mathrm{b}}$ & 2.4 & 13.63 & 68.6 \\
\hline $\mathrm{A} 24^{\mathrm{b}}$ & 1.35 & 6.90 & 74.1 \\
\hline $\mathrm{A} 25^{\mathrm{b}}$ & 2.45 & 12.85 & 50.1 \\
\hline $\mathrm{G} 31^{\mathrm{c}}$ & 2.63 & 6.8 & 72.7 \\
\hline $\mathrm{G} 32^{\mathrm{c}}$ & 1.34 & 7.2 & 69.5 \\
\hline $\mathrm{G} 34^{\mathrm{c}}$ & 1.43 & 6.11 & 74.8 \\
\hline $\mathrm{U} 36^{\mathrm{d}}$ & 2.43 & 8.23 & 68.8 \\
\hline $\mathrm{U} 37^{\mathrm{d}}$ & 2.72 & 7.48 & 77.3 \\
\hline $\mathrm{U} 38^{\mathrm{d}}$ & 2.53 & 12.27 & 56.5 \\
\hline $\mathrm{U} 39^{\mathrm{d}}$ & 2.56 & 10.13 & 69.9 \\
\hline $\mathrm{U} 40^{\mathrm{d}}$ & 2.78 & 7.65 & 71.9 \\
\hline $\mathrm{H} 41^{\mathrm{e}}$ & 2.51 & 10.07 & 75 \\
\hline $\mathrm{H} 42^{\mathrm{e}}$ & 2.36 & 14.08 & 71 \\
\hline $\mathrm{H} 43^{\mathrm{e}}$ & 2.42 & 10.22 & 76 \\
\hline $\mathrm{H} 44^{\mathrm{e}}$ & 1.53 & 6.66 & 69.8 \\
\hline $\mathrm{H} 45^{\mathrm{e}}$ & 2.48 & 9.25 & 74.6 \\
\hline \multicolumn{4}{|c|}{ GJC samples } \\
\hline $\mathrm{P} 1$ & 5.17 & 0.71 & 68.1 \\
\hline $\mathrm{P} 2$ & 5.22 & 0.62 & 66.8 \\
\hline P3 & 5.34 & 0.85 & 71.2 \\
\hline P4 & 5.26 & 0.74 & 70.3 \\
\hline
\end{tabular}

${ }^{\text {a }} \mathrm{N}$, samples prepared in laboratory.

${ }^{b}$ A, commercial samples from Adana region.

${ }^{c} \mathrm{G}$, commercial samples from Gaziantep region.

${ }^{\mathrm{d}} \mathrm{U}$, commercial samples from Sanliurfa region.

${ }^{\mathrm{e}} \mathrm{H}$, commercial samples from Hatay region.

\subsection{FTIR analysis}

A ThermoNicolet Nexus 670 instrument (ThermoNicolet, Madison, WI) equipped with a mercury cadmium telluride A (MCTA) detector, XT-KBr beam-splitter, and OMNIC software was used to measure the spectra of the juice samples. A $0.5 \mathrm{ml}$ aliquot of each sample (PJC, GJC, and adulterated samples) was placed on a multi-bounce $\mathrm{ZnSe}$ crystal. One hundred twenty eight scans at a resolution of $4 \mathrm{~cm}^{-1}$ were taken and averaged over the $4000-650 \mathrm{~cm}^{-1}$ region. A background was collected before each sample was analyzed then subtracted from the sample spectra prior to further analysis.

\subsection{Statistical analysis}

The chemometric analysis was performed with SIMCA software (version 10.5, Umetrics, Sweden). Principal component analysis (PCA) was used for the classification of 
the samples. PCA is a multivariate projection method designed to extract and display the systematic variation in a data matrix X. It is important to accurately determine the number of components that should be included in the model since it is linked to the difference between the degree of fit and the predictive ability. The degree of fit increases as the number of components increases, but the predictive ability does not increase after a certain model complexity. It is therefore important to reach an optimal balance between fit and predictive ability. Significant principal components of each category build the class model, which is computed after a separate scaling for each category (Kramer, 1998). Using PCA class model, Coomans' plot is constructed for the classification and for the differentiation of mixtures from pure pomegranate juice concentrate.

Partial least square (PLS) analysis was used to determine the concentration of the adulterant in PJC. The developed method was confirmed by cross-validation techniques. PLS was also used to correlate chemical analysis data (total soluble solids and titratable acidity) with spectra. PLS regression analysis relates the FTIR absorbance data of each mixture (X block) with the percentages of grape juice concentrate in that mixture ( $\mathrm{Y}$ block).

\section{Results and discussion}

Results of the several chemical analyses for the PJC and GJC samples are displayed in Table 1. The percent titratable acidity of PJC and GJC varied from $5.8 \%$ to $14.27 \%$ and $0.71 \%$ to $0.85 \%$, respectively. Brix values ranged from 50.1 to 77.3 for PJC and from 66.8 to 71.2 for GJC. A previous study using single strength pomegranate juice from Turkey reported $\mathrm{pH}$ values between 3.29 and 3.93 , titratable acidity $(\mathrm{g} / \mathrm{l})$ of $4.58-17.3$, and soluble solids (\%) of $16.00-19.00$ (Poyrazoglu et al., 2002). Pomegranate juices in the former Soviet Union region were found to have titratable acidity of
$0.52-1.6$ and total sugar content of $15.2-20.5 \%$ (Gabbasova \& Abdurazakova, 1969). Other studies (Cemeroglu et al., 1992) also reported on the variability of titratable acidity and total sugar contents in pomegranate juice. Therefore, the range of titratable acidity and Brix values obtained in this study were not unexpected.

FTIR spectra of PJC and GJC samples are shown in Fig. 1. Absorption bands around 1715, 1255 and $915 \mathrm{~cm}^{-1}$ occur due to $\mathrm{C}=\mathrm{O}$ stretching, $\mathrm{C}-\mathrm{O}$ acid stretching, and $\mathrm{O}-\mathrm{H}$ deformation of acids, respectively. $\mathrm{C}-\mathrm{O}$ stretching and - $\mathrm{OH}$ deformation of primary, secondary, and tertiary alcohols result in peaks at 1150, 1100 and $1050 \mathrm{~cm}^{-1}$. The absorption band around $2940 \mathrm{~cm}^{-1}$ belongs to $\mathrm{C}-\mathrm{H}$ stretching. The most important difference between PJC and GJC spectra was found in the 1700 $1800 \mathrm{~cm}^{-1}$ region, which corresponds to the $\mathrm{C}=\mathrm{O}$ stretching mode. The spectral difference in this region was large enough to visually discriminate between pure PJC and GJC samples (e.g. all PJC samples had an absorbance peak in this region and all GJC samples had no absorbance peak). Spectra of two commercial GJC samples obtained from Western Turkey also did not have an absorbance peak in the $1700-1800 \mathrm{~cm}^{-1}$ region.

PLS was used in relating FTIR spectra to chemical analysis results. A good correlation was obtained between FTIR spectra and \% titratable acidity and brix values (Fig. 2a and b), with $R^{2}$ values of 0.9114 and 0.9916 , respectively. Because both values can be determined using the same spectra, which can also be used for the adulteration detection described later, FTIR methods could be useful for routine titratable acidity and total solids measurements.

For evaluating the usefulness of FTIR spectra for authenticating PJC, FTIR spectra (4000-650 $\mathrm{cm}^{-1}$ region) in combination with PCA class analysis were used to classify the commercial PJC samples obtained from four different regions of Southeast Turkey. A Cooman's plot (Fig. 3)

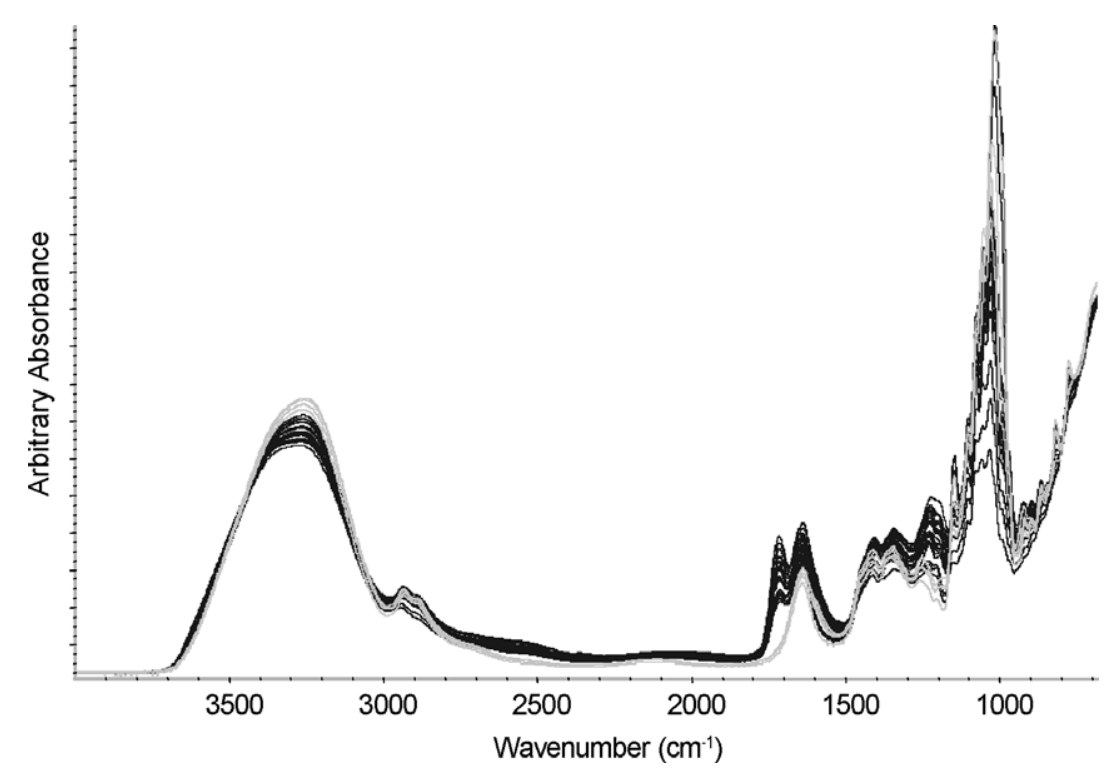

Fig. 1. FTIR spectra of a pomegranate (black) and grape (grey) juice concentrates. 

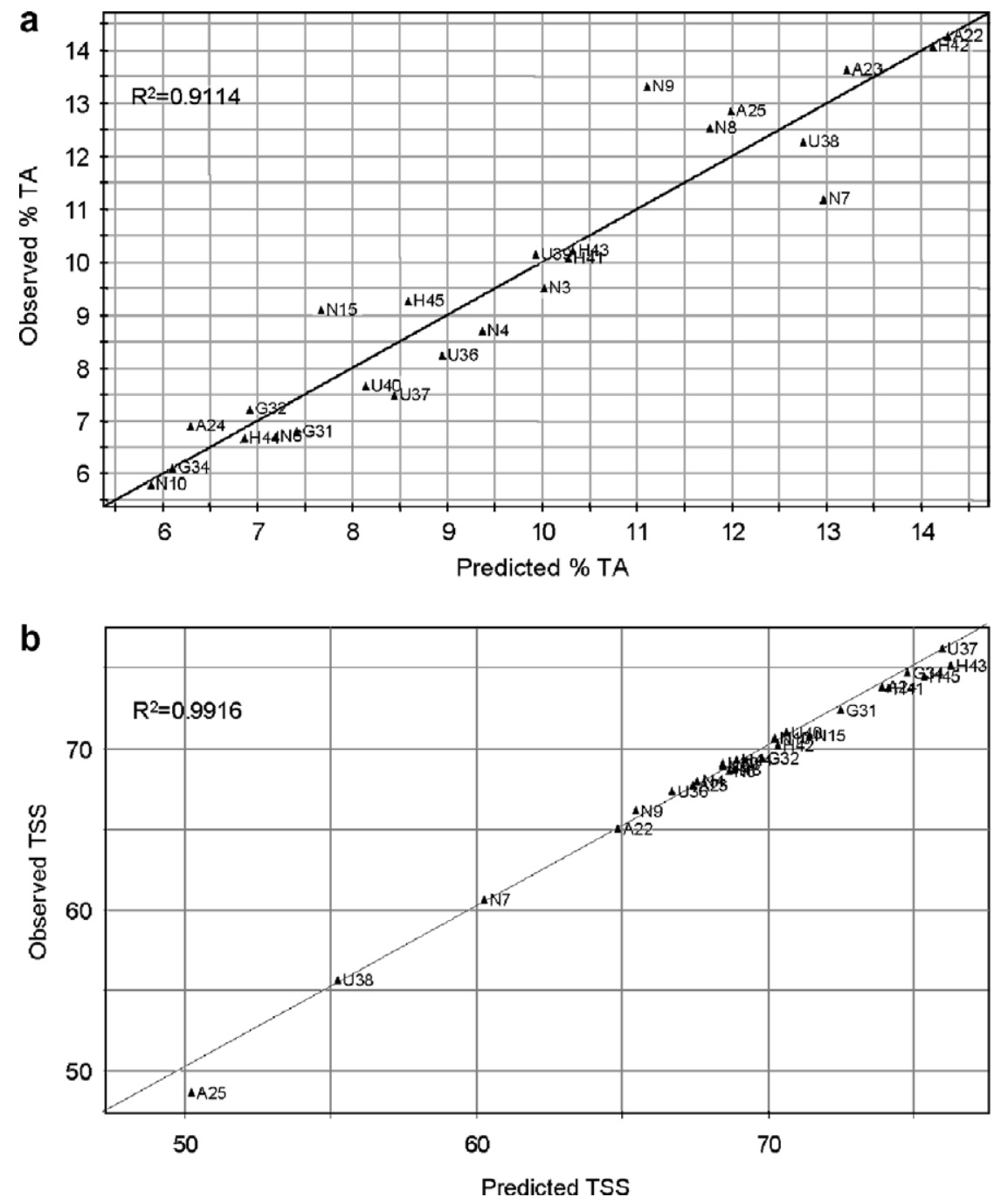

Fig. 2. Correlation between FTIR spectra $\left(4000-650 \mathrm{~cm}^{-1}\right)$ and (a) $\%$ total acidity, (b) total soluble solids.

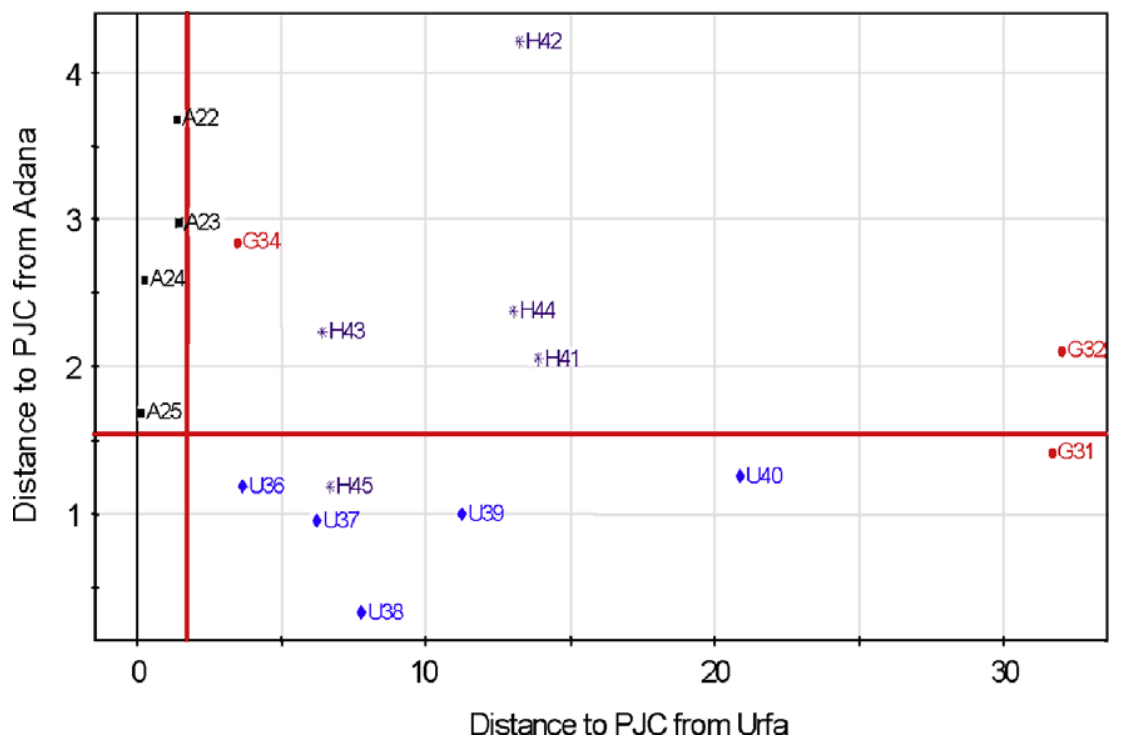

Fig. 3. Cooman's plot showing classification of commercial PJC samples obtained from different regions in Southeast Turkey (A, Adana; G, Gaziantep; U, Sanliurfa; H, Hatay). The PCA was conducted using the entire $4000-650 \mathrm{~cm}^{-1}$ FTIR spectral region. 
was generated to visualize the residual distances of all PJC samples to each of the two PJC samples plotted against each other (Adana and Sanliurfa). Samples that form clusters on a Cooman's plot are more similar than samples with greater distances between them. PJC samples from the Gaziantep region did not form a close cluster in the Cooman's plot, but classification of samples from other regions was more successful, indicated by the closer clustering in the plot. MIR and NIR spectroscopy were also used in differentiation of apple juice according to their varieties and heat treatment applied, and the degree of classification success depended on the variety of apple as it was observed in this study (Reid, Woodcock, O’Donnell, Kelly, \& Downey, 2005).

A Cooman's plot generated from PJC and GJC spectra is shown in Fig. 4. Discrimination using the 1780$1685 \mathrm{~cm}^{-1}$ region, corresponding to the largest observed spectral differences between PJC and GJC in Fig. 1, was relatively better compared to models developed using the $4000-650 \mathrm{~cm}^{-1}$ region. All of the GJC samples were correctly accepted by their class, located in the lower right quadrant of the plot, but several of the PJC samples were outside of their class. However, there is a large distance between PJC and GJC samples, and this is an indication of a successful discrimination. Because two commercial samples of GJC obtained from a different geographical location had similar spectra to the Siverek type of grape, e.g. no absorbance peak in the $1700-1800 \mathrm{~cm}^{-1}$ region, the model developed could have broad application in differentiating PJC and GJC.

After the successful discrimination of PJC from GJC (Fig. 4), PCA class models were also developed for adulterated and pure PJC samples. Again full spectra and only the $1780-1685 \mathrm{~cm}^{-1}$ region were used for classification. Similar results were obtained using these regions. The adulterated PJC samples, containing $2-14 \% \mathrm{vol} / \mathrm{vol}$ GJC, were clustered close to the origin of the general PCA score plot (Fig. 5). Although the adulterated samples fall in the common region on the Cooman's plot, there is still some separation of adulterated and pure samples. Two principal components were used in PCA class models and $R^{2}$ values were 0.99 for both class model.

After the classification of adulterated and pure samples, the adulterant GJC concentration ( $2-14 \% \mathrm{vol} / \mathrm{vol})$ in the pure PJC sample was quantified using PLS analysis. The correlation coefficient of the developed model to predict the adulterant concentration was 0.9751. A diagnostic cross-validation tool was used to determine the validity of the prediction model. The cross-validation was performed by taking one sample out at a time and predicting the concentration of the removed data point. The cross-validation had a reasonable $R^{2}$ value of 0.9597 . For PJC and GJC differentiation, two principal components explained $99 \%$ of the variability. Likewise, for adulterated PJC classification, two principal components explained $99 \%$ of variability.

Traditional chemical analysis techniques such as highperformance liquid chromatography (HPLC) and gas chromatography (GC) as well as newer techniques such as polymerase chain reaction based assays have also been successfully used to determine the authenticity of various fruit juices (Catillo, Caja, \& Herraiz, 2003; Hammond, 2001; Low, McLaughlin, Hofsommer, \& Hammond, 1999; Mooney, Chappell, \& Knight, 2006; Pan, Kilmartin, Smith, \& Melton, 2002). Success of these methods depends on the presence of specific markers that might be present in either adulterant or pure juice. Therefore, arduous extraction steps might be required. IR spectroscopy is a good

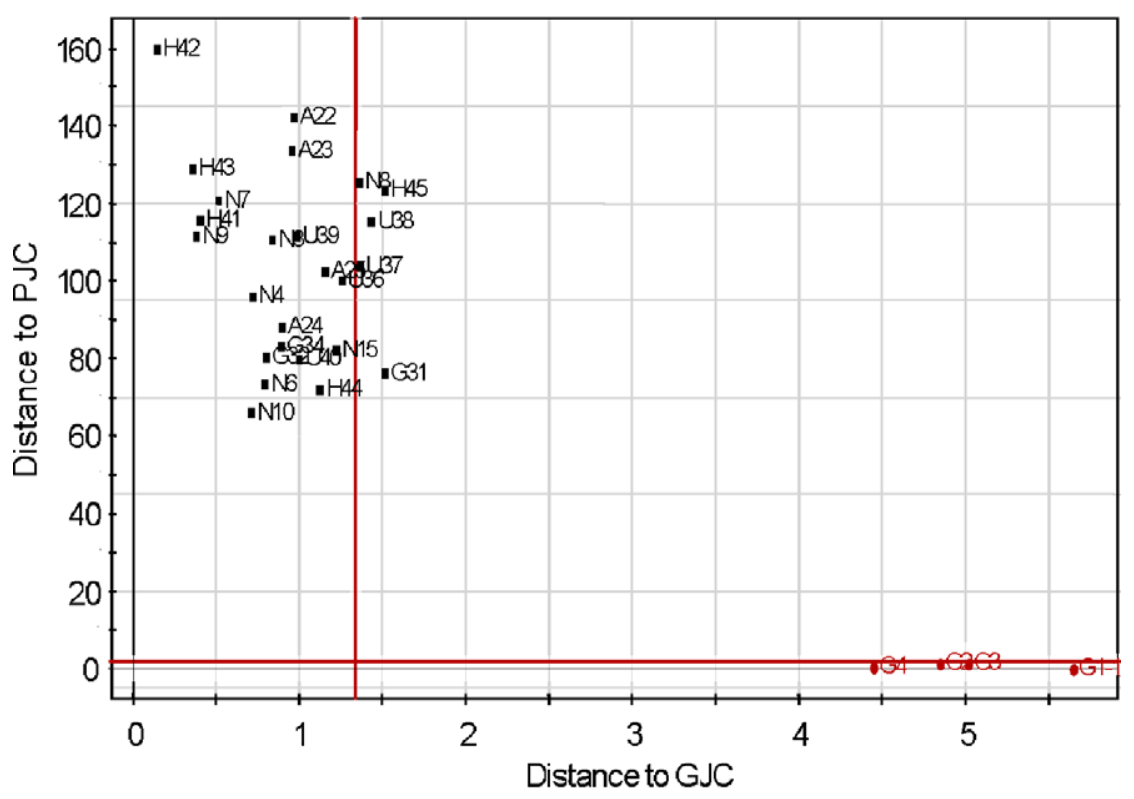

Fig. 4. Cooman's plot showing discrimination of pure PJC and GJC samples. The PCA was conducted using the $1780-1685 \mathrm{~cm}^{-1}$ FTIR spectral region. 

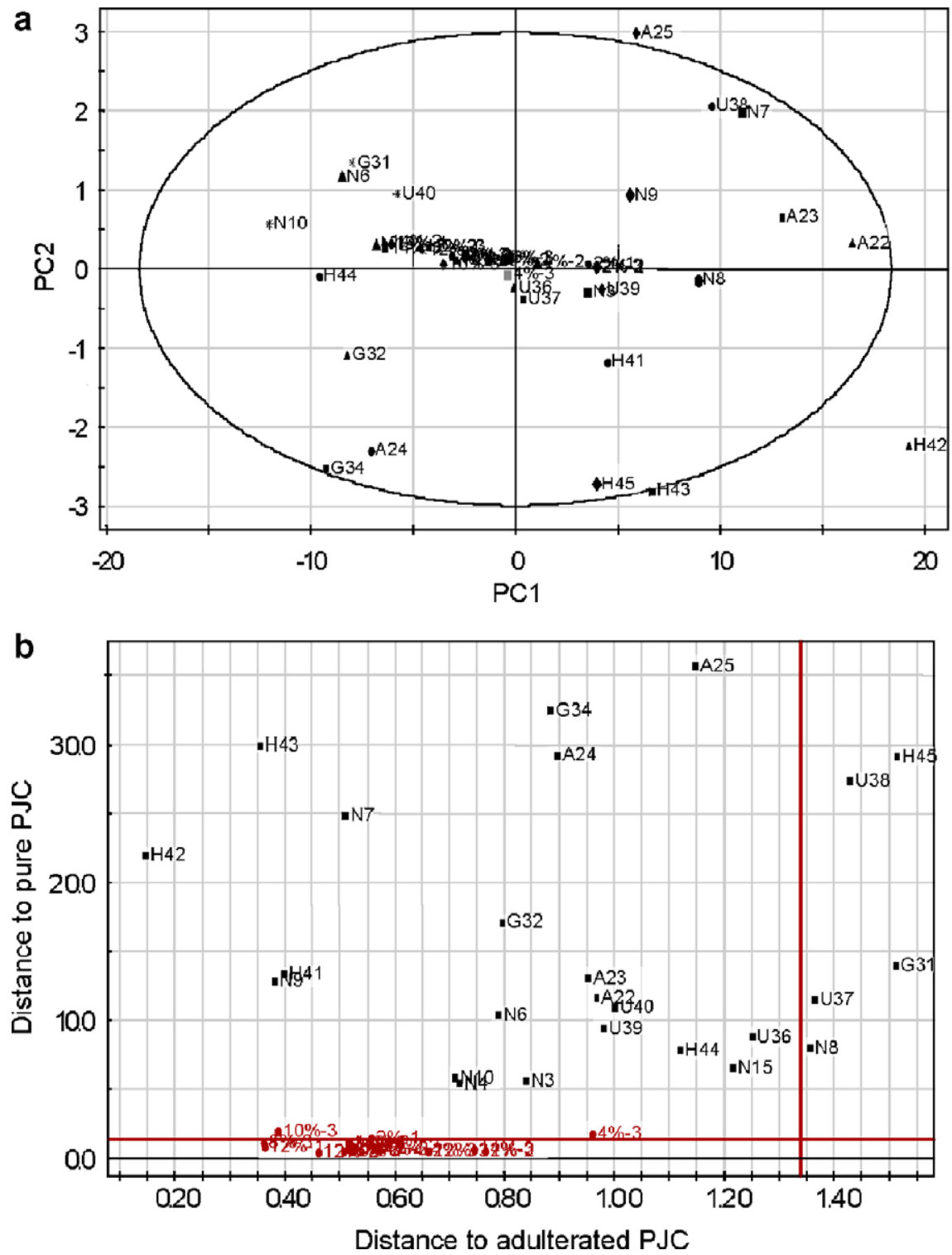

Fig. 5. Discrimination of pure PJC and adulterated PJC (containing 2-25\% GJC): (a) PCA score plot and (b) Cooman's plot showing discrimination of adulterated PJC and pure PJC. PCA was conducted using the $1780-1685 \mathrm{~cm}^{-1}$ FTIR spectral region.

alternative to provide a rapid classification of PJC and GJC. If a sample deviated from the expected spectra for PJC, further analysis could be conducted to identify the type of adulterant present. In conclusion, the FTIR method used in combination with chemometrics provides a promising approach for detecting the adulteration of pomegranate juice concentrate with grape juice concentrate.

\section{References}

AOAC (1980). Official methods of analysis (13th ed.). Washington, DC, USA: Association of Official Analytical Chemists.

Aviram, M., Dornfeld, L., Kaplan, M., Coleman, R., Gaitini, D., Nitecki, S., et al. (2002). Pomegranate juice flavonoids inhibit low-density lipoprotein oxidation and cardiovascular diseases: Studies in atherosclerotic mice and in humans. Drugs Under Experimental and Clinical Research, 28, 49-62.
Aviram, M., Dornfeld, L., Rosenblat, M., Volkova, N., Kaplan, M., Coleman, R., et al. (2000). Pomegranate juice consumption reduces oxidative stress, atherogenic modifications to LDL, and platelet aggregation: Studies in humans and in atherosclerotic apolipoprotein E-deficient mice. American Journal of Clinical Nutrition, 71, 1062-1076.

Catillo, M. L. R., Caja, M. M., \& Herraiz, M. (2003). Use of enantiomeric composition for the assessment of the authenticity of fruit beverages. Journal of Agricultural and Food Chemistry, 51, 1284-1288.

Cemeroglu, B., Artik, N., \& Erbas, S. (1992). Gewinnung von Granatapfelsaft und seine Ausammensetzung. Flussiges Obst, 59, 335-340.

Cemeroglu, B., Artik, N., \& Yunculer, O. (1988). Nar suyu uzerinde arastirmalar. Doga, 12(3), 322-334.

Gabbasova, B., \& Abdurazakova, S. K. (1969). Chemical composition of pomegranate juice. Izvestiya Vysshikh Uchebnykh Zavedenii Pishchevaya Tekhnologiya, 4, 30-31.

Gil, M., Tomas-Barberan, F., Hess-Pierce, B., Holcroft, D., \& Kader, A. (2000). Antioxidant activity of pomegranate juice and its relationship with phenolic composition and processing. Journal of Agricultural and Food Chemistry, 48, 4581-4589. 
Hammond, D. A. (2001). Synergy between liquid chromatographicpulsed amperometric detection and capillary-gas chromatographic methods for the detection of juice adulteration. Journal of AOAC International, 84, 964-975.

Irudayaraj, J., Xu, F., \& Tewari, J. (2003). Rapid determination of invert cane sugar adulteration in honey using FTIR spectroscopy and multivariate analysis. Journal of Food Science, 68, 2040-2045.

Kramer, R. (1998). Chemometric techniques for quantitative analysis. New York: Marcel Dekker.

Low, N. H., McLaughlin, M., Hofsommer, H. J., \& Hammond, D. A. (1999). Capillary gas chromatographic detection of invert sugar in heated, adulterated and heated apple juice concentrates employing the equilibrium method. Journal of Agricultural and Food Chemistry, 47, 4261-4266.

Malik, A., Afaq, F., Sarfaraz, S., Adhami, V., Syed, D., \& Mukhtar, H. (2005). Pomegranate fruit juice for chemoprevention and chemotherapy of prostate cancer. Proceedings of the National Academy of Sciences, 102, 14813-14818.

Melgarejo, P., Salazar, D. M., \& Artes, F. (2000). Organic acids and sugars composition of harvested pomegranate fruits. European Food Research Technology, 211, 185-190.

Mirdehghan, S., \& Rahemi, M. (2007). Seasonal changes of mineral nutrients and phenolics in pomegranate (Punica granatum L.) fruit. Scientia Horticulturae, 111, 120-127.

Mooney, R., Chappell, L., \& Knight, A. I. (2006). Evaluation of a polymerase chain reaction-based heteroduplex assay for detecting the adulteration of processed orange juice with mandarin juice. Journal of AOAC International, 89, 1052-1060.
Noda, Y., Kaneyuki, T., Mori, A., \& Packer, L. (2002). Antioxidant activities of pomegranate fruit extract and its anthocyanidins: Delphinidin, cyanidin, pelargonidin. Journal of Agricultural and Food Chemistry, 50, 166-171.

Ozen, B. F., Weiss, I., \& Mauer, L. J. (2003). Dietary supplement oil classification and detection of adulteration using Fourier transform infrared spectroscopy. Journal of Agricultural and Food Chemistry, 51, 5871-5876.

Pan, G. G., Kilmartin, P. A., Smith, B. G., \& Melton, L. D. (2002). Detection of orange juice adulteration by tangelo juice using multivariate analysis of polymethoxylated flavones and carotenoids. Journal of the Science of Food \& Agriculture, 82, 421-427.

Poyrazoglu, E., Gokmen, V., \& Artik, N. (2002). Organic acids and phenolic compounds in pomegranates (Punica granatum L.) grown in Turkey. Journal of Food Composition and Analysis, 15, 567-575.

Reid, L. M., Woodcock, T., O’Donnell, C. P., Kelly, J. D., \& Downey, G. (2005). Differentiation of apple juice samples on the basis of heat treatment and variety using chemometric analysis of MIR and NIR data. Food Research International, 38, 1109-1115.

Tay, A., Singh, R. K., Khrisnan, S. S., \& Gore, J. P. (2002). Authentication of olive oil adulterated with vegetable oils using Fourier transform infrared spectroscopy. LWT Food Science and Technology, $35,99-103$.

Unal, C., Velioglu, S., \& Cemeroglu, B. (1995). Turk nar sularinin bilesim ogeleri. Gida, 20(6), 339-345.

Vardin, H., \& Fenercioglu, H. (2003). Study on the development of pomegranate juice processing technology: Clarification of pomegranate juice. Nahrung/Food, 47, 300-303. 